\title{
SITUAÇÃO DO ENSINO DA ENFERMAGEM EM DOENÇAS TRANSMISSÍVEIS NO BRASIL*
}

\author{
Maria Rizoneide Negreiros de Araújo ${ }^{\text {i:** }}$ \\ Roseni Rosângela Chompré***
}

ARAUJO, M. R. N. de \& CHOMPRE, R. R. Situação do ensino da enfermagem em doenças transmissiveis no Brasil. Rev. Esc. Enf. USP, 18(2):101-112, 1984.

Estudo sobre a situaçāo do ensino da Enfermagem em Doenças Transmissiveis nos Cursos de Graduação em Enfermagem no Brasil, abrangendo os aspectos: conteúdo pregramático, estratégias didáticas, disposiçāo na estrutura curricular e filosofia no ensinc. Foram enviados questionários a 70 estabelecimentos de ensino de Enfermagem do pais. obtendo-se resposta de 27 deles. As principais conclusoes do trabalho foram: a disciplina Enfermagem em Doenças Transmissiveis é ministrada no 4 ? e 50 semestres; a carga hordria da disciplina varia muito entre as Instituiçōes estudadas, sendo a média de 80 a 120 horas; o ensino é direcionado à área curativa; os aspectos preventivos sāo pouco cnfatıza. dos, predominando como campo de estágio as unidades hospitalares.

\section{INTRODUÇĀO}

No ensino da Enfermagem em Doenças Transmissíveis, tem sido preocupação constante para os docentes, o enfoque a ser abordado, levando-se em consideração a magnitude com que as doenças transmissiveis acometen: a população brasileira. principalmente as incluídas na faixa etária de 0 a 5 anos

Os processos de mudanças curriculares há muito vêm ocorrendo nos cursos de Graduação em Enfermagem, porém, deixa muito aquém uma definı. ção clara e precisa do marco conceitual norteador a ser desenvolvido na nritica profissional do Enfermeiro.

O atual currículo mínimo, Parecer n! 163/72, apesar de incluir Enicrmai gem em Doenças Transmissiveis, exclui a matéria Enfermagem em Saúdi l'i. blica do Tronco Profissional Comum e inclui Saúde Comunitária a ser mins.

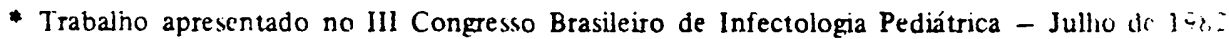
Belo Horizonte - Minas Gerals.

* Diretora da Escola de Enfermagem da Liniversidaúe Federal de Minas Gerais.

*** Professora Assistente do Departamento de Enfermagem Matemo-Infantil e Saúde Públici di 1 . cola de Enfermagem da U'niversidade Federal de Minas Gerais. 
trada no início do curso, o que, na nossa opiniāo, torna a formação dos enfermeiros muito voltada para assistência curativa. Tal fato, tem sido agravado pela forma de ensino centrado em doenças e sintomas. condicionando o Enfermeiro a não atuar na prevenção de doenças.

O Plano Decenal de Saúde para as Américas (Santiago - Chile, 1972) declara que na maioria dos países da América Latina é muito limitado o conhecimento das enfermidades transmissiveis prevalentes, bem como do estado imunitário das populações e dos efeitos que sobre estas têm os programas de controle ou erradicação.

O Programa Nacional de Imunizaçðes (PNI) do Ministério da Saúde ${ }^{3}$ faz uma análise bastante sucinta da situação das doenças transmissíveis de maior prevalência no País e define, como prioridades para atuação, as medidas preventivas aplicáveis com base na existência de imunobiológicos eficazes ao seu controle.

Apesar dos recursos existentes, as medidas de prevenção dessas doenças não têm sido operacionalizadas de modo a influenciar significativamente os indices de morbidade da população susceptível. Estima-se que a expressão da mortalidade por doenças transmissíveis seja de $40 \%$ do obituário geral do Pais ${ }^{3}$.

A ocorrência das doenças transmissf́veis está diretamente liga đa a múltiplos fatores relacionados ao agente, ao suscetível e ao meio ambiente.

AROUCA $^{1}$ cita, em seu trabalho, estudos que demonstram ser maior a contribuição dos fatores ambientais na ocorrência de doenças, chegando a abordar a questão somente em termos de agente hospedeiro. Nos trabalhos por ela citados, os fatores sócio-económicos, educacionais e sanitários são de importáncia incontestável, sendo sua determinação na modificação da saúde comparável àqueles obtidos pelas açðes dos Serviços de Saúde.

Dentro dessa concepçâo, os trabalhos de PESSOA ${ }^{5}$, LEAVELL \& CLARCK $^{2}$, AROUCA ${ }^{1}$ e MINISTÉRIO DA SAÚDE ${ }^{3}$ destacam como principais fatores que contribuem para a manutenção dos altos indices de morbimortalidade por doenças transmissíveis, os seguintes:

- mudanças ecológicas abruptas, condiçð̃es sanitárias desfavoráveis à sobrevivência do homem, baixa cobertura vacinal daquelas enfermidades controláveis por imunizantes, desigualdades sociais e economicas.

Assim compreendida a multicausalidade das doenças transmissíveis, a formação do Enfermeiro não deve ser embasada simplesmente na capacitação técnica e cientifica, mas deve, também, levar a refletir criticamente sobre os problemas psicossociais, econômicos e culturais inerentes à sua prática profissional, de forma que ele possa assumir um compromisso social de mudança.

Em face das preocupaçes analisadas o presente trabalho tem por finali- 
dade estudar a situação do ensino de Enfermagem em Doenças Transmissíveis nos cursos de Graduaçđo em Enfermagem e Obstetrícia, nos aspectos referentes a conteúdo programático, estratégias didáticas, disposição na estrutura curricular e filosotia de ensino.

\section{OBJETIVOS}

Identificar em que perfodo do curso de Graduação é ministrada a disciplina Enfermagem em Doenças Transmissíveis.

Identificar o número de horas determinado para o desenvolvimento da disciplina.

Verificar o enfoque dado no desenvolvimento do conteúdo programático da disciplina. Identificar se as açðes de imunizaçōes são ministradas dentro do conteúdo da disciplina Enfermagem em Doenças Transmissíveis.

Verificar os locais onde é desenvolvido ensino prático da disciplina.

Identificar as principais dificuldades encontradas no ensino da disciplina.

\section{METODOLOGIA}

\section{População estudada}

Pensou-se, no início, em realizar o estudo proposto tendo como universo a totalidade das Escolas de Enfermagem do País, conforme listagem publicada no Boletim de Normas e Notícias do Conselho Federal de Enfermagem - COFEN. Foram enviados formulários de coleta de dados para 70 Estabelecimentos de Ensino de Enfermagem, obtendo-se respostas de 27 deles.

\section{Coleta de dados}

A coleta de dados foi realizada através de formulários enviados a Diretores das Escolas de Enfermagem, no período de março a junho de 1982, pelo correio.

Esses questionários, em anexo, continham perguntas relativas aos objetivos do trabalho.

\section{RESULTADOS E DISCUSSÃO}

Por ser a Enfermagem em Doenças Transmissíveis uma disciplina obrigatória no Currículo Mínimo do Curso de Enfermagem, conforme Resolução n? 04/72 do Conselho Federal de Educação, partiu-se do pressuposto que seria fácil conseguir as informaçð̃es desejadas; foi, porém, verificado o contrário, posto que apenas 27 Escolas devolveram o questionário preenchido, como se vê pela Tabela 1 . 
Tabela 1 - Percentual de questionários enviados e recebidos, por regiāo do pais.

\begin{tabular}{lccc}
\hline \multicolumn{1}{c}{ Regioes } & Questionários & $\%$ \\
& Enviados & Recebidos & \\
\hline Norte & 3 & 2 & 67,0 \\
Nordeste & 15 & 6 & 40,0 \\
Centro-Oeste & 3 & 1 & 33,0 \\
Sudeste & 19 & 14 & 74,0 \\
Sul & 10 & 4 & 40,0 \\
\hline Total & 50 & 27 & 54,0 \\
\hline
\end{tabular}

Na Tabela 2, observa-se que, em relação ao período em que é ministrada a disciplina Enfermagem em Doenças Transmissíveis, apenas 25 Diretores de Escola responderam a essa questão - $40 \%$ das Escolas estudadas ministramna no 5 ? período; $20 \%$ no 4 \%; $16 \%$ no 6 e e 79 e $4 \%$ no 4 \% e 9 ? períodos. Em algumas delas, a disciplina é desenvolvida em mais de um perfodo, sendo a teoria ministrada separada da parte prática.

Tabela 2 - Período em que é oferecida a disciplina enfermagem em doenças transmissíveis nos cursos de graduação em enfermagem no país.

\begin{tabular}{lccccccc}
\hline Regiáo & $\mathbf{3 0}$ & $\mathbf{4 9}$ & $\mathbf{5 9}$ & $\begin{array}{c}\text { Período } \\
\mathbf{6 9}\end{array}$ & $\mathbf{7 9}$ & $\mathbf{8 9}$ & $\mathbf{9 9}$ \\
\hline Norte & 1 & - & - & 1 & - & - & - \\
Nordeste & - & - & 4 & - & 1 & - & 1 \\
Centro-Oeste & - & - & - & - & 1 & - & - \\
Sudeste* & - & 4 & 6 & 2 & - & - & - \\
Sul & - & 1 & - & 1 & 2 & - & - \\
\hline Total & 1 & 5 & 10 & 4 & 4 & - & 1 \\
\hline
\end{tabular}

* duas Escolas ñ̃o responderam a esta pergunta

Pode-se constatar que, na Região Norte, essa disciplina é oferecida com uma carga horária que varia de 120 a 160 horas; nas Regioes Nordeste e Sudeste, a concentração está em torno de 80 a 120 horas; e, na Região Sul, de 40 a 80 horas. Deixa-se de abordar a Região Centro-Oeste por ter-se obtido informaçōes de apenas uma Escola. Encontra-se ainda, variação de carga horária total de 45 a 335 horas, predominando em todas as regióes a média de 80 a 120 horas (Tabela n? 3). 
Tabela 3 - Carga horária da disciplina enfermagem em doenças transmissíveis segundo o número de escolas de enfermagem por região do país.

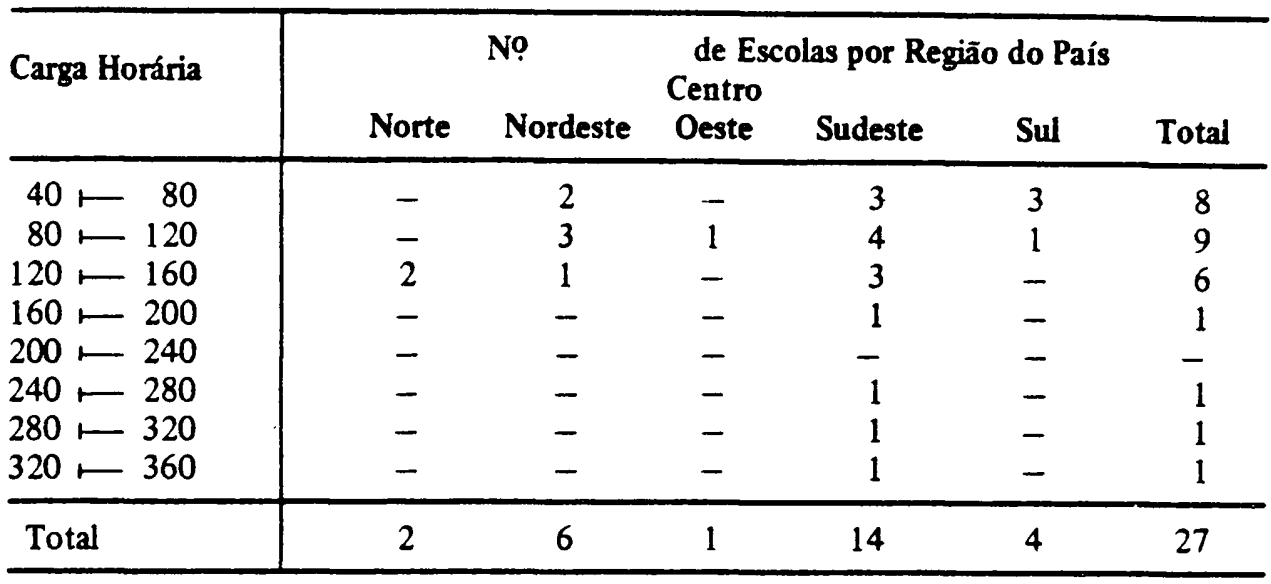

Considerando a problemática das doenças transmissíveis no País e, em especial, aquelas endèmicas por Região, não se encontra justificativa para a grande variação em termos de carga horária. Por outro lado, uma carga horária de 45 horas leva 2 indagar como são abordados os aspectos de prevenção, promoção e recuperação da saúde em tão ínfima carga horária, a menos que seja apresentada uma estrutura curricular em que essa abordagem das doenças transmissíveis estivesse diluída ao longo do currículo.

Analisando em separado a carga horária teórica ministrada nas Escolas estudadas, verifica-se que essa variação também é bastante acentuada, ou seja, de 1 a 20 horas até 60 ou mais horas, demonstrando maior concentração na faixa de 20 a 40 horas, representada por 16 das Escolas estudadas, o que se vê pela Tabela 4 .

Tabela 4 - Carga horária teórica da disciplina enfermagem em doenças transmissiveis dos cursos de graduação em enfermagem por região do país.

\begin{tabular}{l|ccccc}
\hline \multirow{2}{*}{ Regizes } & \multicolumn{5}{c}{ Carga Horária } \\
& menos de $\mathbf{2 0 h}$ & $\mathbf{2 0 - 4 0 ~ h}$ & $\mathbf{4 0 - 6 0 ~ h}$ & $\mathbf{6 0}$ e mais & Total \\
\hline Norte & - & 2 & - & - & 2 \\
Nordeste & - & 4 & - & 2 & 6 \\
Centro-Oeste & - & 1 & - & - & 1 \\
Sudeste & 1 & 6 & 4 & 3 & 14 \\
Sul & 1 & 3 & - & - & 4 \\
\hline Total & 2 & 16 & 4 & 5 & 27 \\
\hline
\end{tabular}


Imunização, como uma das medidas de controle em doenças transmissíveis, é ensinada em 33\% das Escolas estudadas, incorporada à Enfermagem de Doenças Transmissiveis e, em 30\% em Enfermagem de Saúde Pública. Nas demais Escolas, esse tema é ministrado em disciplinas correlatas à Enfermagem de Saúde Pública. As demais escolas onde Imunização é ministrada fora dessas duas disciplinas, sua abordagem é feita em disciplinas introdutórias ao Curso de Enfermagem (Tabela n! 5).

Tabela 5 - Disciplinas que incluem o conteúdo de imunizaçðes, nos cursos de graduação em enfermagem, por região do país.

\begin{tabular}{|c|c|c|c|c|c|c|}
\hline $\begin{array}{l}\text { No de Escolas por regiso } \\
\text { Disciplinas }\end{array}$ & Norte & Nordeste & $\begin{array}{l}\text { Centro } \\
\text { Oeste }\end{array}$ & Sudeste & Sul & Total \\
\hline $\begin{array}{l}\text { Enfermagem em Doenças } \\
\text { Transmissiveis }\end{array}$ & 1 & 1 & - & 7 & - & 9 \\
\hline $\begin{array}{l}\text { Enfermagem de Saúde } \\
\text { Pública }\end{array}$ & 1 & 4 & - & 2 & 1 & 8 \\
\hline Enfermagem Pediátrica & - & 1 & - & - & 1 & 2 \\
\hline Saúde da Comunidade & - & - & 1 & 2 & - & 3 \\
\hline $\begin{array}{l}\text { Introdução à Saúde } \\
\text { Pública }\end{array}$ & - & - & - & 2 & 1 & 3 \\
\hline $\begin{array}{l}\text { Enfermagem Preventiva } \\
\text { e Comunitária }\end{array}$ & - & - & - & 1 & - & 1 \\
\hline Enfermagem Social & - & - & - & - & 1 & 1 \\
\hline Total & 2 & 6 & 1 & 14 & 4 & 27 \\
\hline
\end{tabular}

O Programa Nacional de Imunizaçðes ${ }^{3}$ (1973) analisa a atividade "imunizaçōes" como a principal medida de controle das doenças transmissíveis. Nesse sentido, é salutar que tal medida de controle seja abordada em disciplina introdutória do curso de Enfermagem, no bojo de todas as medidas empregadas no controle das doenças transmissfveis, sem, contudo, perder a visão dos determinantes sociais e económicos da ocorrência dessas doenças em nosso País.

Segundo PAIM et alii ${ }^{4}$, a formação do Enfermeiro está quase totalmente voltada para a assistencia hospitalar. Ao examinar as ementas, objetivos e programaçôes das 27 Escolas estudadas, observa-se que, na sua totalidade, a disciplina Enfermagem em Doenças Transmissiveis é desenvolvida dentro desse enfoque. Algumas ementas e objetivos são tais como "Capaci ação do atendimento às necessidades básicas do individuo afetado por doençás infecto-contagiosas, utilizando, para tal, técnicas exeqüiveis e concernentes a esse 
atendimento", "Assistência de Enfermagem baseada nas necessidades bio-psicossociais do paciente" e "Assistência de Enfermagem aos portadores de doenças infecto-contagiosas causadas por vírus, bactérias, protozoários e helmintos”, colocam claramente a priorização na assistência ao indivíduo doente. Apenas uma escola aborda enfaticamente em seus objetivos o enfoque do ensino de Enfermagem em Doenças Transmissíveis aos níveis de prevenção primária, secundária e terciária e açōes a nível curativo: "Aplicar os métodos de prevenção e controle das Doenças Transmissíveis ao indivíduo, grupo e comunidade; executar a metodologia da assistência de enfermagem com pacientes portadores de doenças transmissíveis em hospital, ambulatório e em domicílio e conhecer programas de controle de doenças transmissíveis a nivel central, regional e local".

Os resultados mostram que, apesar de alguns Diretores de Escolas afirmarem que abordam as medidas preventivas aos níveis primário, secundário, $\mathrm{e}$ terciário, nas programaçōes enviadas as mesmas enfocam de maneira prioritária os aspectos epidemiológicos, sinais e sintomas de doenças e assistência de enfermagem a pacientes acometidos dessas enfermidades.

Tabela 6 - Carga horária e locais de prática da disciplina enfermagem em doenças transmissiveis dos cursos de graduação em enfermagem, por região do país.

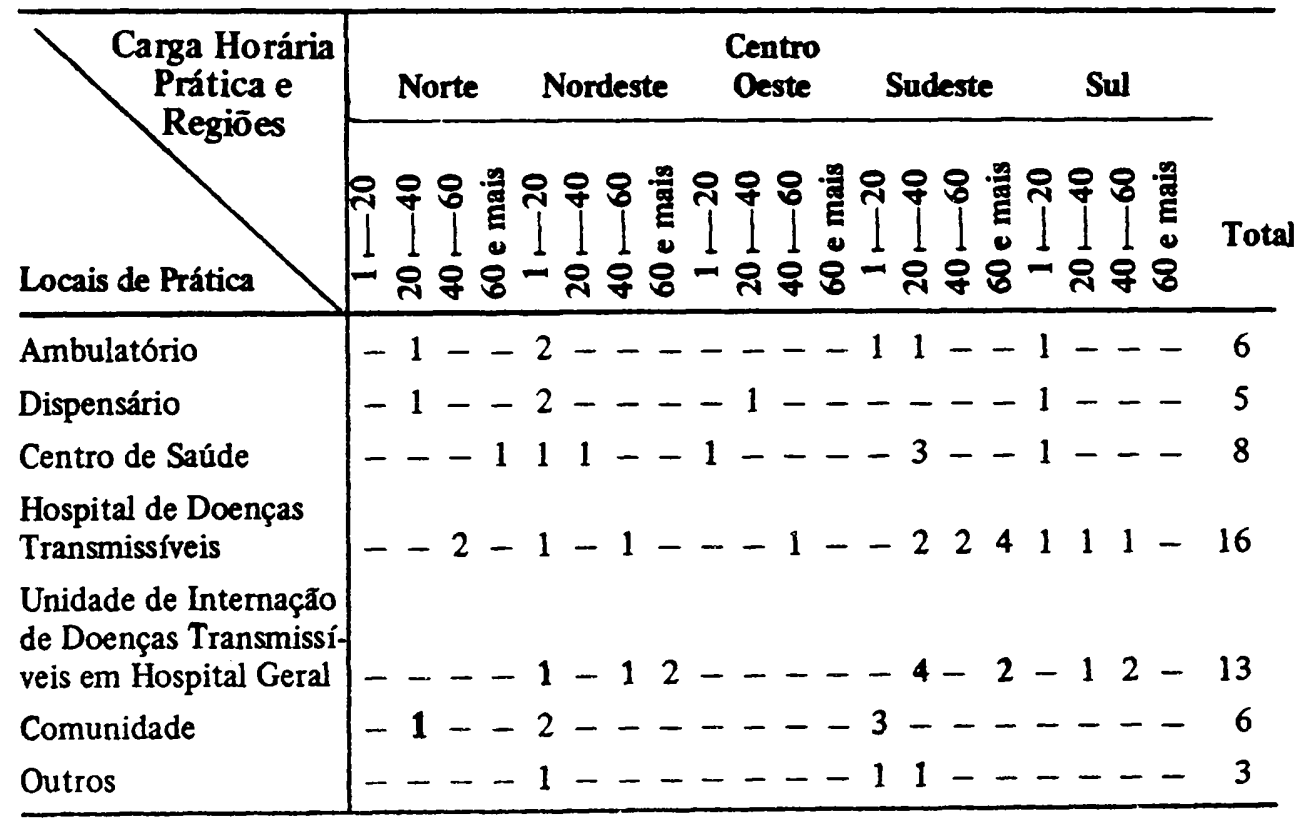


Outro ponto observado foi que a carga horária está sendo desenvolvida dentro de Hospital Especializado ou em Unidades de Internação de doenças infecto-contagiosas. Essa prática encontra-se centrada na prestação da assistência de enfermagem a pacientes portadores de enfermidades infecto-contagiosas, com a utilização de técnicas empregadas em isolamento. Tal situação também é observada quando da análise da listagem de dificuldades apresentadas no desenvolvimento da disciplina, na qual foi possivel detectar a deficiência de campo de estágio, pela ausência de hospitais especializados para esse fim. Caso se considere que o atendimento do paciente portador de doenças transmissiveis, principalmente daquelas patologias de maior ocorrência no País, não se processa a nível hospitalar, pode-se perceber que o aluno não está no local onde realmente poderia vivenciar as experiências e ter uma ação a nível de controle e assisténcia aos portadores de doenças infecto-contagiosas. São também mencionadas, como dificuldades, as deficiências de profissionais, em qualidade e quantidade, para o desempenho da docência em Enfermagem em Doenças Transmissiveis e a escassez de material bibliográfico e audio-visual especificos, bem como uma defasagem observada entre o ensino teórico ministrado em sala de aula e o observado nos campos de prática. Neste sentido, quando se questionou o alcance dos objetivos propostos pela disciplina, 78\% dos Diretores de Escolas afirmaram que estes sãc alcançados parcialmente, em virtude das dificuldades apontadas (Tabelas $\mathrm{n}$ ? $\mathrm{s} 7 \mathrm{e}$ $8)$.

Tabela 7 - Alcance dos objetivos da disciplina enfermagem em doenças transmissíveis de acordo com as regioes do país.

\begin{tabular}{l|cccc}
\hline \multirow{2}{*}{ Região } & \multicolumn{3}{|c}{ Alcance dos Objetivos } & \multirow{2}{*}{ Total } \\
\cline { 2 - 5 } & Integralmente & Parcialmente & Náo-Alcançados & \\
\hline Norte & - & 2 & - & 2 \\
Nordeste & 3 & 3 & - & 6 \\
Centro-Oeste & - & 1 & - & 1 \\
Sudeste & 2 & 12 & - & 14 \\
SuJ & 1 & 3 & - & 4 \\
\hline Total & 6 & 21 & & 27 \\
\hline
\end{tabular}


Tabela 8 - Dificuldades encontradas no desenvolvimento da disciplina enfermagem em doenças transmissiveis, sezundo os diretores das escolas de enfermagem, por regides do país.

\begin{tabular}{|c|c|c|c|c|c|}
\hline $\begin{array}{l}\text { Degizes do País } \\
\text { Dificuldades Encontradins }\end{array}$ & Norte & Nordieste & $\begin{array}{l}\text { Centro- } \\
\text {-Oeste }\end{array}$ & Sundoste & Sul \\
\hline 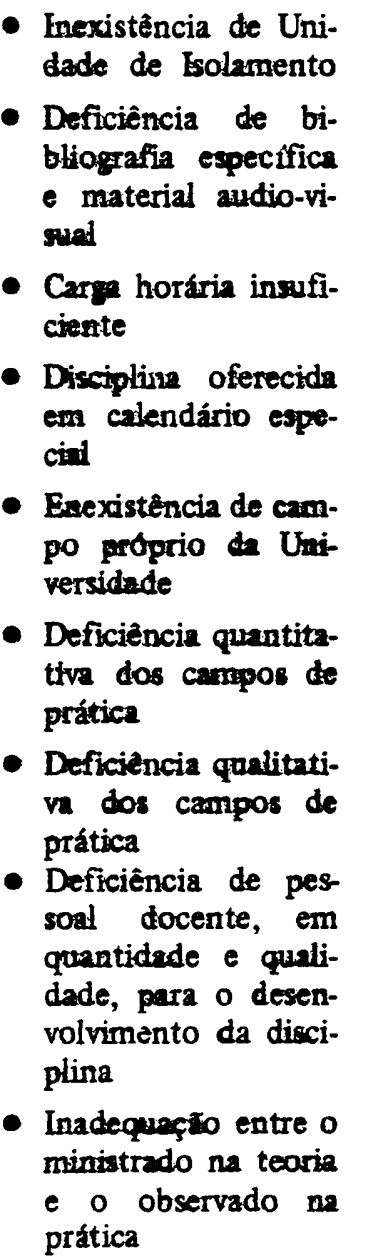 & $\mathbf{X}$ & $\mathbf{x}$ & $\begin{array}{l}\mathbf{X} \\
\mathbf{X}\end{array}$ & $\begin{array}{l}\mathbf{X} \\
\mathbf{X}\end{array}$ & $\mathbf{X}$ \\
\hline
\end{tabular}

Considerando que as doenças transmissiveis sto um agravo à saúde da população brasileira, constituindo um dos problemas de Saúde Pública e, ainda, considerando que a sua ocorrência nzo está ligada exchusivamente aos fatores agente/hospedeino, muito mais ligado aos fatores sócio-conômico-culturais, esperava-se encontrar, pelo levantamento efetuado, que a forma- 
ção do Enfermeiro estivesse voltada para aqueles aspectos; o detectado, porém, foi uma formaçăo voltada quase exclusivamente para os fatores agente/hospedeiro e atuando nos níveis secundário e terciário de atenção à saúde.

\section{CONCLUSÕES}

1. A disciplina Enfermagem em Doenças Transmissíveis é ministrada no 4 ? e 50 períodos ou semestres, na maioria das Escolas estudadas $(60 \%)$.

2. Há grande variação na carga horária do programa de Enfermagem em Doenças Transmissíveis, nas diversas Escolas de Enfermagem do País, sendo a média de 80 a 120 horas.

3. Apesar das doenças transmissiveis constituirem ainda hoje um relevante problema de Saúde Pública, necessitando de utilização de medidas que visem sua prevenção e controle, a formação do Enfermeiro está balizada e direcionada para atuar na prestação da assistencia a pacientes acometidos por enfermidades infecto-contagiosas, principalmente na área hospitalar.

4. Existe preocupação pouco significativa quanto à abordagem preventiva a ser incluída nos conteúdos programáticos da disciplina Enfermagem em Doenças Transmissfveis. Considerando que os problemas inerentes a essa abordagem extrapolam a esfera da simples relação agente/hospedeiro, conclui-se que se faz necessária a adoção de um programa globalizado, com enfase nos determinantes sócio-econômicos e culturais do processo saúde/doença.

5. Na maioria das Escolas, o ensino das imunizações está distribuído entre as disciplinas Enfermagem em Doenças Transmissiveis (33\%) e Enfermagem de Saúde Pública (30\%).

6. As Unidades Hospitalares predominam como sampos de estágio no ensino da Enfermagen em Doenças Transinissíveis, nas Escolas de Enfermagem do Brasil estudadas na presente investigação.

7. As dificuldades levantadas pelos docentes ligados à disciplina Enfermagem em Doenças Transmissiveis. parecem ter relação direta com o enfoque e metodologia definidos para o desenvolvimento do processo-ensino-aprendizagem nas Escolas estudadas.

\section{RECOMENDAÇOES}

Com base nas análises apresentadas, recomenda-se:

1. Que o profissional de Enfermagem seja preparado para atuar com eficiència térnicá e. também, com capacidade crítica, de modo a contribuir efetivamente para a mudança do quadro da morbimortalidade das doenças transmissiveis em nosso Pals. 
2. Que as programaçðes da Disciplina Enfermagem em Doenças Transmissiveis sejam respaldadas por estudos da nosologia prevalente em cada região.

3. Que o enfoque do ensino de Enfermagem em Doenças Transmissíveis seja dirigido para a análise dos determinantes do processo saúde/doença, a fim de capacitar o aluno para atuar em açōes de nível primário, secundário e terciário.

4. Que os profissionais envolvidos com o ensino de Enfermagem em Doenças Transmissiveis realizem trabalhos cientificos, de forma a contribuir para a formação de recursos desta área.

ARAOJO, M. R N. de \& CHOMPRE, R. R. Study of nursing teaching in common diseases in Brazil. Rev. Esc. Enf. USP, Såo Paulo, 18(2):101-112, 1984.

The authors of the given work, present the result of a study (investigation) carried out in 27 Schools of Nursing and Obstetrics in Brazil and about how the subject "infections diseases" is taught and administered.

\section{REFERÊNCIAS BIBLIOGRÁFICAS}

1. AROUCA, A. T. Análise dos determinantes das cond içōes de saúde da população brasileira. In: Saúde e medicin no Brasil: contribuição para um debate. 2. ed. Rio de Janeiro, GRAAL, 1979.

2. LEAVELL, H. \& CLARK, E. E. Modicin Preventiva. Rio de Janeiro, Mc Graw-Hill do Brasil, 1977.

3. MINISTERIO DA SAODE. Programa Nacional de Imunizaçóes. Brasília, DF, 1973.

4. PAIM, L. et alii. As inovaçōes no ensino superior de enfermagem face à assistência à saúde da população - possibilidade e limitaçðes. CONGRESSO BRASILEIRO DE ENFERMAGEM, 30, Belém, 1978. Anais. Belém, Associação Brasileira de Enfermagem, 1978. p.111-5.

5. PESSOA, S. Ensaios médicos sociais. São Paulo, CEBES-HUCITEC, 1978. 


\section{ANEXO}

UNIVERSIDADE FEDERAL EM MINAS GERAIS - ESCOLA DE ENFERMAGEM DEPARTAMENTO DE ENFERMAGEM MATERNO-INFANTIL E DE SAÜDE PÚBLICA

1. Faculdade/Escola:

2. Em que per íodo do Curso de Graduação a disciplina Enfermagem em Doenças Transmiss fveis é oferecida em sua Escola?

3. Qual a carga horária da disciplina Enfermagem em Doenças Transmissiveis?

3.1 Carga Horária Total. ......... horas

3,2 Carga Horária Teórica ....... horas

3.3 Carga Horária Prática ........ horas

4. Quais os principais assuntos abordados no Programa da Disciplina Enfermagem em Doenças Transmissiveis? (anexar programa)

5. Como são enfocados os aspectos preventivos no conteúdo da disciplina Enterıнubu... em Doenças Transmiss f́veis?

6. As açōes de imunizações săo ministradas dentro da disciplina Enfermagem em Doenças Transmiss iveis?
$\operatorname{SIM}()$
NÃO( )

6.1 Em caso afirmativo, qual a carga horária teórica e prática destinada a esse conteúdo?

Teórica...... horas Prática ....... horas

6.2 Em caso negativo, em que disciplina é enfocado esse conteúdo?

7. Onde é desenvolvida a parte prática da disciplina Enfermagem em Doenças Transmissíveis?
Ambulatórios
Dispensários
Centro de Saúde
Hospitais de Doenças Infecciosas
Unidade de Internação de Doenças Infeccio.
sas dentro Hospital Geral
Comunidade
Outios

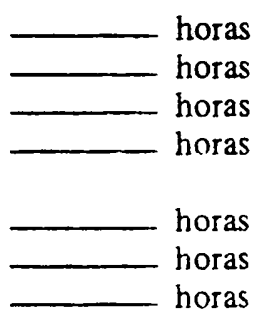

8. Cite as principais dificuldades encontradas no desenvolvimento da disciplina Enfermagem em Doenças Transmissíveis, em sua Escola.

9. Os objetivos da disciplina Enfermagem em Doenças Transmissíveis têm sido alcançados

( ) Integralmente

( ) Parcialmente

( ) Não têm sido alcançados

Caso tenham sido alcançados (parcialmente ou não tenham sido alcançados), indique as principais causas. 